\title{
Serum anti-Müllerian hormone (AMH) levels correlate with infrarenal aortic diameter in healthy older men: is AMH a cardiovascular hormone?
}

\author{
Nicola A Dennis', Gregory T Jones², Yih Harng Chong', Andre M van Rij ${ }^{2}$ \\ and Ian S McLennan' \\ ${ }^{1}$ Department of Anatomy, Otago School of Medical Sciences, Brain Health Research Centre and ${ }^{2}$ Department of \\ Surgery, Dunedin School of Medicine, University of Otago, Lindo Ferguson Building, Great King Street, PO Box 913 \\ Dunedin 9054, New Zealand
}

Correspondence should be addressed to I S McLennan Email ian.mclennan@otago.ac.nz

\begin{abstract}
Anti-Müllerian hormone $(\mathrm{AMH})$ is a gonadal hormone present in the blood in men and pre-menopausal women. AMH regulates male sexual differentiation but has no putative function in adulthood. In recent studies, high $\mathrm{AMH}$ levels are associated with absence of cardiovascular disease in men and smaller atherosclerotic burden in monkeys. Mechanistically, $\mathrm{AMH}$ has downstream convergence with known regulators of the cardiovascular system, while the specific receptor for $\mathrm{AMH}$ is present in murine aorta and the human heart. Our primary objective was to examine whether AMH levels in healthy men correlated with the physical characteristics of their aorta. Our secondary aim was to document whether men with distinct vascular disorders expressed different levels of $\mathrm{AMH}$. Serum AMH assayed by ELISA in 153 men (54-93 years) free from vascular disease inversely correlated with the ultrasonographic diameters of the distal- $(r=-0.22, P=0.006)$ and mid-infrarenal aorta $(r=-0.26, P=0.008)$. This association was similar in magnitude but opposite to that of body surface area (largest known determinant of aortic diameter) and independent of known cardiovascular risk factors. This relationship is specific to $A M H$, as inhibin $B$, a Sertoli cell hormone-like $\mathrm{AMH}$, did not correlate with aortic diameter $(r=-0.04, P=0.66)$ despite partially correlating with $\mathrm{AMH}$. Among men with known vascular disease, higher $\mathrm{AMH}$ levels were associated with varicose vein disease, while men with higher levels of $A M H$ were underrepresented in the abdominal aortic aneurysm relative to the healthy cohort. These findings identify $\mathrm{AMH}$ as a novel putative regulator of the cardiovascular system.
\end{abstract}
Key Words
- hormone action
- cardiovascular
- testis
- menopause

Journal of Endocrinology (2013) 219, 13-20

\section{Introduction}

Anti-Müllerian hormone (AMH; or Müllerian inhibiting substance) is a gonadal hormone that is dimorphic during development and later in life. It induces part of the male phenotype, with its role in male development extending into childhood (Catlin et al. 1997, MacLaughlin \& Donahoe 2004, Wang et al. 2009, Wittmann \& McLennan 
2011). At puberty, the production from the testes diminishes whereas ovarian production begins (Lee et al. 1996, Aksglaede et al. 2010, Kelsey et al. 2011, Seifer et al. 2011), with the result that men and women have similar levels of AMH in their blood. The levels of AMH in adults are less than those present in boys but are nevertheless sufficient to influence some AMH-sensitive cells in vitro (Wang et al. 2005). Ovarian production of AMH ceases as women enter menopause (Visser et al. 2012), with the result that $\mathrm{AMH}$ is dimorphic in the elderly (Chong et al. 2012, 2013).

The presence of AMH in adult blood has been known for over 20 years, yet no function has been attributed to it. The cardiovascular system is emerging as a potential site for AMH action. High levels of AMH associate with the absence of cardiovascular disease in elderly men (Chong et al. 2013) and with a small plaque diameter in a rhesus model of atherosclerosis (Appt et al. 2012). These observations have no proven causality. AMH is, however, a plausible regulator of the cardiovascular system, as its downstream signalling is common with the bone morphogenetic proteins, which regulate vascular development and maintenance (Lowery \& de Caestecker 2010, Cai et al. 2012). Furthermore, the mRNA for the AMH-specific receptor, $A M H R 2$, is present in the human heart (Ricci et al. 2010), with cardiac and aortic expression also occurring in mice (Dennis 2012).

One of the classical tests used to identify the function of hormones is whether a physiological parameter varies in relationship with the concentration of the hormone. AMH in blood has a half-life in excess of a day (Griesinger et al. 2012), and level of AMH in an individual is therefore stable compared with most other hormones. AMH may therefore be a regulator of traits that only vary slowly over time, such as the remodelling of blood vessels during ageing. If so, clues to the functions of $\mathrm{AMH}$ may be obtained by determining whether AMH associates with either the physical characteristics of their blood vessels or particular cardiovascular conditions. We have therefore examined serum samples from a vascular genetic study to determine i) whether $\mathrm{AMH}$ levels correlate with the abdominal aortic diameter in healthy men and ii) whether men with different vascular disorders have different levels of AMH.

\section{Subjects and methods}

\section{Ethics statement}

All study participants gave written informed consent, and approval for the study was obtained from the Multi-Region
Ethics Committee of New Zealand. The investigation conforms with the principles outlined in the Declaration of Helsinki.

\section{Study populations}

This study derived its population from various cohorts with the same community: a healthy elderly group of men without vascular disease, men with different vascular disorders and a control group of aged men with various health statuses.

Healthy cohort The healthy cohort comprised 153 community-dwelling men aged 54-93 years with no history of vascular disease. These men were screened for peripheral arterial disease (PAD), carotid artery disease and carotid intima-media thickness. Participants with an ankle-brachial pressure index (ABI) of $<0.9$ or $>1.3$ were excluded from further analysis as were those with a carotid stenosis $>50 \%$. Men were recruited from the Otago community and assessed by the Otago Vascular Diagnostics Laboratory and the Vascular Surgical outpatient's clinic at the Dunedin Hospital. A detailed questionnaire recording each individual's current medications, BMI, waist-to-hip ratio (WHR), body surface area (BSA, calculated using the Mosteller formula), blood pressure and vascular risk factor history, including hypertension, hyperlipidaemia, diabetes mellitus, other vascular disease and pack-year smoking history (one packyear equates to smoking one packet of 20 cigarettes daily for 1 year) was collected. A blood sample was drawn and both plasma and serum were stored at $-80{ }^{\circ} \mathrm{C}$ for subsequent analyses. Plasma lipids and high-sensitivity C-reactive protein (hs-CRP) were assessed using Roche enzymatic assays in an accredited laboratory. The characteristics of the participants are summarised in Table 1.

Vascular disease cohorts Three cohorts of men were recruited with a single dominant distinct vascular pathology: varicose vein disease (VVD), abdominal aortic aneurysm (AAA) and PAD. Each cohort was recruited from the same Otago community as the healthy cohort. The age of VVD cohort ranged from 22 to 90 years $(n=70)$ and was diagnosed by venous duplex scanning and plethysmography. The AAA cohort (age range 54-88 years, $n=69$ ) was recruited as part of a wider vascular research study and included men with a maximal infrarenal aortic diameter $>3 \mathrm{~cm}$ on ultrasound or a history of abdominal aorta repair following a AAA rupture. The PAD cohort (aged 40-87 years, $n=70$ ) had symptomatic disease

Published by Bioscientifica Ltd. 
Table 1 Characteristics of the participants. The data are the mean \pm S.E.M. of 153 healthy men, with the range indicated in parenthesis

Age (years)
Height $(\mathrm{m})$
Weight $(\mathrm{kg})$
BMI $\left(\mathrm{kg} / \mathrm{m}^{2}\right)$
Hip $(\mathrm{cm})$
Waist $(\mathrm{cm})$
Waist-to-hip ratio
BSA $\left(\mathrm{m}^{2}\right)$
LDL $(\mathrm{mmol} / \mathrm{l})$
HDL $(\mathrm{mmol} / \mathrm{l})$
Total cholesterol (mmol/l)
Triglyceride (mmol/l)
Smoking (pack-years)
Intimal-medial thickness $(\mathrm{mm})$
hs-CRP (mg/l)

$71.4 \pm 6.3(54-93)$

$1.75 \pm 0.07(1.59-1.92)$

$81.7 \pm 13.6(55-123)$

$26.6 \pm 3.6(19.6-38.0)$

$103.5 \pm 8.5(82-139)$

$98.2 \pm 10.3(79-138)$

$0.95 \pm 0.05(0.81-1.11)$

$1.99 \pm 3.6(1.56-2.54)$

$3.04 \pm 0.07(0.5-6.0)$

$1.24 \pm 0.03(0.6-2.3)$

$5.05 \pm 0.07(2.7-7.8)$

$1.59 \pm 0.06(0.5-6.1)$

$9.5 \pm 1.36(0.0-78.8)$

$0.7 \pm 0.01(0.5-1.3)$

$3.07 \pm 0.76(0.1-35.9)$

BSA, body surface area.

or a resting $\mathrm{ABI}<0.7$. Each cohort contained different participants. The height, weight, BMI, WHR and BSA of the cohorts were not significantly different from each other and from the healthy cohort (Supplementary Table 1 , see section on supplementary data given at the end of this article).

Control cohorts for the disease cohorts Each disease cohort had an age-matched comparison cohort derived from the healthy cohort (above) and men (aged 22-50 years) recruited as part of a wider study assessing $\mathrm{AMH}$ levels in the Otago community (Chong et al. 2013). The men were healthy without major chronic medical disorders and had no diagnosed diseases affecting their pituitary-testicular axis.

\section{Blood vessel measurements}

The external diameter of the abdominal aorta was measured with ultrasound (4-7 MHz) at three sites: suprarenal (immediately distal to the superior mesenteric branch ostium), mid-infrarenal and distal-infrarenal ( $1 \mathrm{~cm}$ proximal to the aortic bifurcation). The intimalmedial thickness of the common carotid arteries was measured $1 \mathrm{~cm}$ proximal to the bifurcation (ultrasound, 7-12 MHz) in accordance with the Mannheim consensus statement (Touboul et al. 2007). The presence of carotid stenosis, within the internal carotid arteries (ICA), was assessed using the Australasian Society for Ultrasound in Medicine (ASUM) clinical protocol (D14) for colour duplex ultrasound extracranial carotid disease (carotid stenosis score) (www.asum.com.au).

\section{Serum analysis}

Serum AMH levels were measured in duplicate in three batches, with the investigator being blinded to the characteristics of the men. The first batch $(n=40)$ was measured with MIS/AMH ELISA (Diagnostic System Laboratories (Webster, TX, USA), DSL-10-14400, analytical sensitivity $0.04 \mathrm{pmol} / \mathrm{l}, 0.006 \mathrm{ng} / \mathrm{ml}$ ). Beckman Coulter purchased DSL, and the remaining samples $(n=113)$ were measured with the enzyme immunoassay AMH/MIS Kit (Beckman Coulter (Fullerton, CA, USA), A16507, analytical sensitivity $1 \mathrm{pmol} / \mathrm{l}, 0.14 \mathrm{ng} / \mathrm{ml}$ ), which utilised the same MABs as the discontinued DSL kit. All samples were measured without prior dilution, according to the manufacturer's instructions. These kits have been reported to give similar results (La Marca et al. 2009), with this being confirmed in our laboratory (Supplementary Figure 1, see section on supplementary data given at the end of this article).

Serum inhibin B levels were measured in duplicate with an ELISA (Beckman Coulter, A81303, analytical sensitivity $1 \mathrm{pg} / \mathrm{ml}$ ). The levels of vitamin D (25 hydroxyvitamin D) in the serum of 113 of the men were measured in duplicate using an ELISA (ALPCO Immunoassays (Windham, $\mathrm{NH}$, USA), K2109, analytical sensitivity $=3.2 \mathrm{nM}, 1.28 \mathrm{ng} / \mathrm{ml}$ ). The data obtained with this kit are linear with respect to both LC-MS (ELISA estimate $=1.2082 \times$ LC-MS estimate $+1.2965, r=0.92$ ) and HPLC (ELISA estimate $=0.9466$ $\times$ HPLC estimate $-7.0509, r=0.888)$ estimates. The specificity of the kit is $100 \%$ for $25(\mathrm{OH}) \mathrm{D} 3$ and $24,25-\mathrm{OH}$-vitamin D2 and $68 \%$ for $25(\mathrm{OH}) \mathrm{D} 2$, with no significant crossreactivity to vitamin D2 (ergocalciferol; 0.3\%). There was insufficient serum available in the other 40 participants to measure vitamin D levels.

\section{Statistical analysis}

The association between AMH and cardiovascular parameters was examined by linear regression, with potential confounders analysed using partial correlation. Both parametric and nonparametric tests yielded similar results. The difference between means for subgroups (e.g. men taking statin medication or not) was examined using the Kolmogorov-Smirnov test. Calculations were performed in either Stata/IC 11.2 (StataCorp LP, College Station, TX, USA) or IBM SPSS Statistics (IBM Corp.). Any $P$ values of $<0.05$ are recorded in the tables and figures.

\section{Results}

The mean serum AMH level in 153 healthy older men aged 54-93 years was $27 \mathrm{pmol} / \mathrm{l}$ and ranged from undetectable

Published by Bioscientifica Ltd 
to $104 \mathrm{pmol} / \mathrm{l}$. Most men had AMH levels that were similar to those previously described for this age group (Aksglaede et al. 2010). Three of the cohort (aged 69, 80 and 84 years) had undetectable AMH levels ( $<1 \mathrm{pmol} / \mathrm{l})$, suggesting that a minority of elderly men do not produce AMH (see also Chong et al. (2013)).

\section{AMH levels inversely correlate with infrarenal aortic diameter}

Serum AMH concentration negatively correlated with the abdominal aortic diameter at the distal- and midinfrarenal sites $(r=-0.22, P=0.006 ; r=-0.26, P=0.008$ respectively; Fig. $1 \mathrm{~A}$ and $\mathrm{B}$ ) and with the maximum of the two measurements, maximum-infrarenal $(r=-0.29$, $P=0.002$; Fig. 1C), indicating that men with low AMH levels tend to have larger aortic diameters. There was no correlation between the reference suprarenal aortic diameter and AMH levels $(r=-0.10, P=0.24$; Fig. 1D). The maximum-infrarenal diameter is reported hereafter, as AMH levels correlated more strongly with this measure. The AMH levels were measured using two closely related ELISAs, with the strength and significance of the above correlations being similar if the analysis is restricted to the 113 samples analysed with the Beckman Coulter Kit (Table 2).
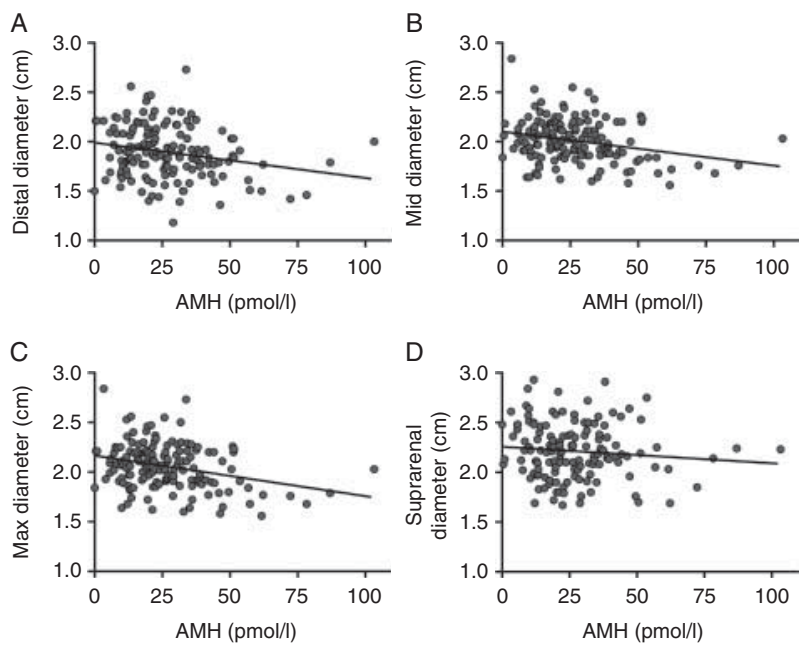

\section{Figure 1}

$\mathrm{AMH}$ level correlated with infrarenal aortic diameter in healthy men. Aortic diameter was measured using ultrasound in 153 healthy men. AMH levels correlated with aortic diameter at the distal-infrarenal site (A: $r=-0.22$, $P=0.006)$, the mid-infrarenal site (B: $r=-0.26, P=0.008$ ) and with the maximum of the two measurements ( $C: r=-0.29, P=0.002$ ). There was no correlation between AMH levels and aortic diameter at the suprarenal site (D: $r=-0.10, P=0.24$ ). The black line indicates best fit with linear regression. $1 \mathrm{ng} / \mathrm{ml}$ AMH $=7.14 \mathrm{pmol} / \mathrm{l}$.

\section{Aortic diameter did not correlate with known covariants of AMH}

Both AMH and inhibin B are produced by the Sertoli cells in the testes, with the levels of these hormones in men partially correlated with each other, as expected $(r=0.22$, $P=0.006)$. However, the size of the aorta did not correlate with inhibin B levels ( $r=-0.04, P=0.66$; Table 3$)$ and the inclusion of both $\mathrm{AMH}$ and inhibin $\mathrm{B}$ in a linear regression model did not degrade the association with AMH.

$\mathrm{AMH}$ levels in adults are mildly seasonal under the influence of vitamin D (Dennis et al. 2012). Seasonality is an unlikely confounder of the study, as the majority of the cohort was examined during winter with few participants examined in summer. Consistent with this, the aortic diameter did not correlate with the vitamin $\mathrm{D}$ levels in men $(r=-0.04, P=0.671$; Table 3$)$.

\section{AMH does not correlate with various known determinants of aortic diameter}

Body size is a strong determinant of aortic diameter (Pearce et al. 1993, Sonesson et al. 1994). Consistent with this, the aortic diameter correlated with multiple measures of body size (Table 3), with BSA having the strongest association in this cohort. There was no correlation between AMH levels and height $(r=0.08, P=0.312)$, weight $(r=0.11, P=0.171)$ BMI $(r=0.09, P=0.257)$ or BSA $(r=0.11, P=0.171)$, indicating that AMH levels did not correlate with these physical characteristics in men.

In multiple linear regression analysis, the inclusion of BSA increased the strength of the association between AMH levels and aortic diameter (Table 4), indicating that body size and AMH independently correlate with aortic diameter. The strength of the AMH correlation with aortic diameter was as strong as that to BSA, but in the opposite direction. The inclusion of age as a variable in the model did not significantly change this association (Table 4).

Aortic diameter did not significantly correlate with atherosclerotic risk factors such as LDL $(r=-0.11$, $P=0.166)$, HDL $(r=-0.04, P=0.651)$, total cholesterol ( $r=-0.11, P=0.167)$, triglyceride levels $(r=-0.01$, $P=0.913)$ and smoking pack-years $(r=0.01, P=0.897)$ in this healthy cohort. Similarly, these factors did not correlate with AMH levels.

A minority $(n=37)$ of the men had been prescribed statin medication. There was no association between AMH levels and statin consumption (Kolmogorov-Smirnov test, $D=0.22, P=0.11)$. AMH levels did not significantly

Published by Bioscientifica Ltd. 
Table 2 AMH correlations to the diameter of the aorta. The data were analysed by Pearson's correlation $(r)$

\begin{tabular}{|c|c|c|c|c|}
\hline \multirow[b]{2}{*}{ Correlate } & \multicolumn{2}{|c|}{$\begin{array}{c}\text { Beckman } \\
\text { Coulter Kit }(n=113)\end{array}$} & \multicolumn{2}{|c|}{ Full data set $(n=153)$} \\
\hline & $r$ & $P$ & $r$ & $P$ \\
\hline Distal-infrarenal & -0.25 & 0.009 & -0.22 & 0.006 \\
\hline Mid-infrarenal & -0.29 & 0.001 & -0.26 & 0.008 \\
\hline Maximal-infrarenal & -0.34 & $<0.001$ & -0.29 & 0.002 \\
\hline
\end{tabular}

correlate with the carotid intimal-medial thickness $(r=-0.14, P=0.07)$.

hs-CRP is an inflammatory marker associated with aortic size (Vainas et al. 2003) and a biomarker for cardiovascular disease (Rietzschel \& De Buyzere 2012). Nine men had CRP levels exceeding $10 \mathrm{mg} / \mathrm{l}$ (reference range $<3 \mathrm{mg} / \mathrm{l})$, indicating either acute inflammation or very high risk for development of cardiovascular disease (Pearson et al. 2003). AMH levels in these men were unremarkable (range 6-38 pmol/l). In the other 144 men, hs-CRP correlated with aortic diameter $(r=0.23$, $P=0.0002)$, but not with AMH levels $(r=-0.12$, $P=0.168)$. AMH and hs-CRP were independently correlated with aortic diameter when CRP was added to the linear regression model (Table 4 ).

Although generally healthy, 47 men reported a history of hypertension. There was no significant difference in AMH levels between men with hypertension and those without (Kolmogorov-Smirnov test, $D=0.18, P=0.217$ ). However, information was lacking on the extent or duration of hypertension in these men, which may have improved the analytical approach. The level of $\mathrm{AMH}$ in men did not correlate with their current blood pressure measurement $(r=0.03, P=0.715)$, although there was a non-significant trend for AMH levels to negatively associate with $\mathrm{ABI}(r=-0.16, P=0.064)$. The aortic diameter did not associate with either current blood pressure $(r=-0.02$, $P=0.836)$ or with the ABI $(r=0.02, P=0.778)$.

\section{Men with VVD have high levels of AMH}

If $\mathrm{AMH}$ regulates some aspect of cardiovascular function, men with different levels of AMH may exhibit different propensities for developing various vascular disorders. We therefore compared the level of AMH in men with VVD $(n=70)$, PAD $(n=70)$ and AAA $(n=69)$ to healthy men. The age distribution in the disease cohorts varied (Supplementary Table 1), and each cohort therefore had its own age-matched control $(n=70)$. The AMH levels in the VVD cohort were significantly elevated to its control cohort and to those in men with AAA and PAD (Student's t-test, $P=0.003$; Fig. 2A). This association was further tested by combining the control cohorts and comparing them with the three disease cohorts using a one-way ANOVA, with correction for age. The four cohorts were significantly different $\left(F_{3,401}=5.85, P=0.001\right)$, with the VVD cohort being significantly different from the other three cohorts in a Tukey's post-hoc test $(P=0.001$ vs AAA, $P=0.004$ vs control and $P=0.006$ vs $P A D)$.

We then compared the distribution of AMH levels in the disease cohorts (Fig. 2B). The distributions in AAA and VVD cohorts were significantly different from the healthy men (Kolmogorov-Smirnov test, controlling for age: AAA: $D=0.21, P=0.034$; VVD: $D=0.23, P=0.011$ ), even though each of the distributions was statistically normal. Men with higher levels of $\mathrm{AMH}$ were overrepresented in the VVD cohort and moderately underrepresented in the AAA cohort (Fig. 2B).

\section{Discussion}

$\mathrm{AMH}$ is present in the blood of men and pre-menopausal women, but no hormonal function has been ascribed to it in adults. We here report that serum AMH levels in healthy older men inversely correlated with the diameter of their abdominal aorta. We also report that the distribution of AMH values in men differed depending on vascular disease. These observations, in conjunction with other recent correlative studies (Appt et al. 2012, Chong et al. 2013), provide a rationale for undertaking biomedical studies to determine whether $\mathrm{AMH}$ is a causal regulator of the aorta and other blood vessels.

Table 3 Correlates with the maximum infrarenal aortic diameter

\begin{tabular}{|c|c|c|}
\hline Correlate & $\boldsymbol{r}$ & $\boldsymbol{P}$ \\
\hline $\mathrm{AMH}$ & -0.30 & 0.000 \\
\hline Inhibin B & -0.04 & 0.66 \\
\hline Vitamin D & -0.04 & 0.67 \\
\hline Age & 0.14 & 0.084 \\
\hline Height & 0.22 & 0.007 \\
\hline Weight & 0.31 & 0.000 \\
\hline $\mathrm{BMI}$ & 0.25 & 0.002 \\
\hline BSA & 0.31 & 0.000 \\
\hline Hip & 0.31 & 0.000 \\
\hline Waist & 0.31 & 0.000 \\
\hline Waist-to-hip ratio & 0.11 & 0.16 \\
\hline
\end{tabular}

The data were analysed by Pearson's correlation $(r)$, with significant $P$ values presented in bold. The sample size was 153 , except for vitamin $D$ which was 113 
Table 4 Linear regression models for the predication of maximum infrarenal aortic diameter. Four linear regression models were constructed to examine the interactions between correlates with the maximum-infrarenal diameter. The partial correlations of the individual predictors are recorded in the right column

\begin{tabular}{|c|c|c|c|c|c|}
\hline \multirow{2}{*}{$\begin{array}{l}\text { Model } \\
\text { no. }\end{array}$} & \multicolumn{2}{|c|}{ Model } & \multirow[b]{2}{*}{ Correlate } & \multicolumn{2}{|c|}{ Partial correlation } \\
\hline & $r^{2}$ & $P$ & & $r$ & $P$ \\
\hline 1 & 0.09 & $<0.001$ & $\mathrm{AMH}$ & -0.30 & $<0.001$ \\
\hline 2 & 0.22 & $<0.001$ & $\begin{array}{l}\text { AMH } \\
\text { BSA }\end{array}$ & $\begin{array}{r}-0.37 \\
0.37\end{array}$ & $\begin{array}{l}<0.001 \\
<0.001\end{array}$ \\
\hline 3 & 0.25 & $<0.001$ & $\begin{array}{l}\text { AMH } \\
\text { BSA } \\
\text { Age }\end{array}$ & $\begin{array}{r}-0.36 \\
0.39 \\
0.18\end{array}$ & $\begin{array}{r}<0.001 \\
<0.001 \\
0.028\end{array}$ \\
\hline 4 & 0.29 & $<0.001$ & $\begin{array}{l}\text { AMH } \\
\text { BSA } \\
\text { Age } \\
\text { hs-CRP }\end{array}$ & $\begin{array}{r}-0.35 \\
0.40 \\
0.19 \\
0.18\end{array}$ & $\begin{array}{r}<0.001 \\
<0.001 \\
0.028 \\
0.090\end{array}$ \\
\hline
\end{tabular}

BSA, body surface area; hs-CRP, high sensitive C-reactive protein. Significant results are in bold.

The Sertoli cells of the testes produce two hormones, $\mathrm{AMH}$ and inhibin $\mathrm{B}$, but only $\mathrm{AMH}$ is associated with the aortic diameter. Consequently, the correlation is specifically with AMH rather than with the global Sertoli cell function. Total testosterone level also does not correlate with aortic diameter, although the level of free testosterone in older men has a weak inverse association ( $r=-0.008$; Yeap et al. 2010). Luteinizing hormone (LH) has a weak positive association with aortic diameter ( $r=0.012$; Yeap et al. 2010), but the relevance of this to the current study is unclear as little is known about the regulation of $\mathrm{AMH}$ in men.

The strength of the association between $\mathrm{AMH}$ and maximal infrarenal aortic diameter was similar but opposite to the effect of BSA, which was the strongest correlate in this cohort. It was also independent of various other known correlates of aortic diameter, such as age, hs-CRP levels and body size (Paivansalo et al. 2000). This is consistent with AMH being a novel regulator of the aorta, but definitive proof of this will require the underlying mechanism to be elucidated.

The current study is cross-sectional and is therefore not instructive regarding causation, including when any putative causal event occurred. The levels of AMH in boys and men are highly variable between individuals, with the differences between boys being stable during pre-adolescent development (Aksglaede et al. 2010, Morgan et al. 2011). AMH is a putative regulator of the growth trajectory of boys (Morgan et al. 2011), with growth trajectory a determinant of adult cardiovascular disease (Barker 1995, Forsen et al. 2004). Consequently, it is plausible that this relationship between AMH level in men and their aortic size may reflect a role for $\mathrm{AMH}$ in aortic development. This postulate requires that the AMH level in an adult is tightly influenced by his levels during development. Equally, the aorta is a dynamic structure, whose size and shape changes during adult life (Pearce et al. 1993, Lederle et al. 1997, Paivansalo et al. 2000, Jones 2011). AMH may therefore be linked to the dynamic remodelling of the aorta during the ageing process.

In summary, $\mathrm{AMH}$ concentration is a strong, novel correlate to the diameter of the abdominal aorta, with this correlation being independent of known physical and metabolic determinants of the aorta. AMH is widely used as a clinical marker of gonadal status, but its role in blood
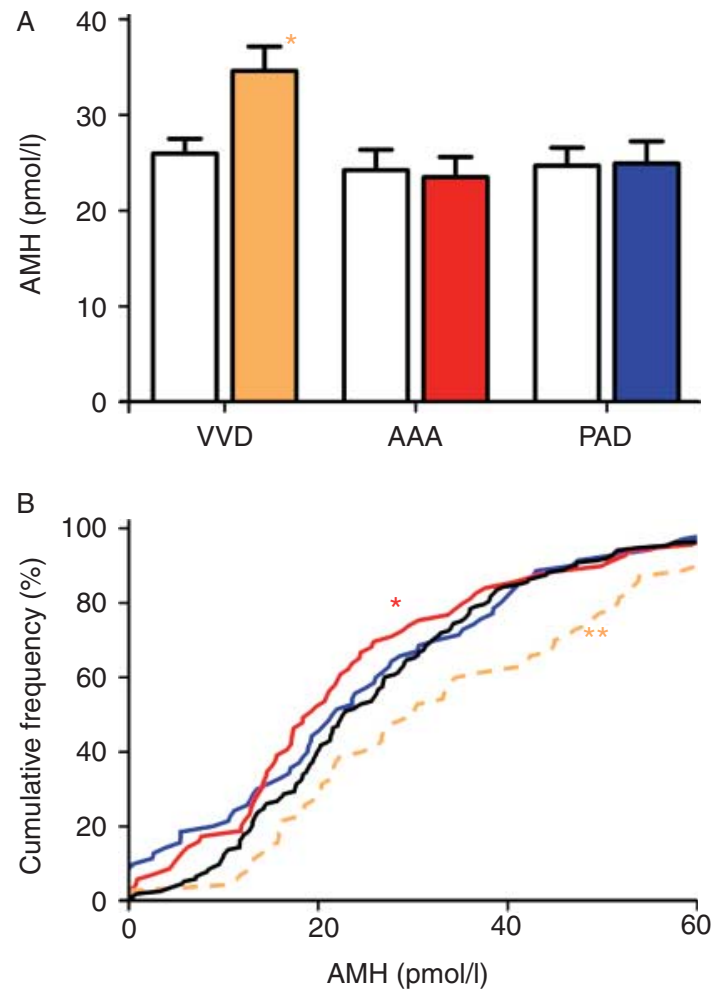

Figure 2

The distributions of AMH levels in men vary with their cardiovascular status. (A) The level of AMH in men with VVD (orange bar, $n=70$ ), AAA (red bar, $n=69$ ) and PAD (blue bar, $n=70$ ) was compared with age-matched healthy control (open bar) men. Each bar represents the mean \pm s.E.M. *Significant difference to the control group (Student's $t$-test, $P=0.003$ ). $1 \mathrm{ng} / \mathrm{ml} \mathrm{AMH}=7.14 \mathrm{pmol} / \mathrm{l}$. (B) The distribution of $\mathrm{AMH}$ levels of 197 healthy men (black) was compared with 70 men with VVD (orange), 70 men with PAD (blue) and 69 AAA patients (red). *AMH levels were significantly lower in AAA patients $(D=0.21, P=0.034)$ than controls and significantly higher in men with VVD $(D=0.229, P=0.011$, Kolmogorov-Smirnov comparison, controlling for age).

Published by Bioscientifica Ltd. 
has been largely unexplored due to a lack of putative functions. The current correlations are consistent with $\mathrm{AMH}$ being a hormonal regulator of either vascular development or homeostasis, like other members of the TGF $\beta$ superfamily.

\section{Supplementary data}

This is linked to the online version of the paper at http://dx.doi.org/10.1530/ JOE-13-0125.

\section{Declaration of interest}

The authors declare that there is no conflict of interest that could be perceived as prejudicing the impartiality of the research reported.

\section{Funding}

This study was funded by the Ministry of Business, Innovation and Employment, New Zealand (NERF grant to I S M et al.). The vascular genetics study was supported by programme grant funding from the Health Research Council of New Zealand to G T J.

\section{Author contribution statement}

N A D and Y H C measured the hormones. G T J and A M R designed and collected the vascular cohort. $\mathrm{Y} \mathrm{H} \mathrm{C}$ designed and collected the Otago cohort. I S M, N A D and Y H C drafted the manuscript, with input and final approval from all authors.

\section{Acknowledgements}

The authors thank the participants for donating their blood and Mrs Nicola Batchelor, Ms Marion Weimar and Mrs Vicky Phillips for their excellent technical assistance.

\section{References}

Aksglaede L, Sorensen K, Boas M, Mouritsen A, Hagen CP, Jensen RB, Petersen JH, Linneberg A, Andersson AM, Main KM et al. 2010 Changes in anti-Müllerian hormone $(\mathrm{AMH})$ throughout the life span: a population-based study of 1027 healthy males from birth (cord blood) to the age of 69 years. Journal of Clinical Endocrinology and Metabolism 95 5357-5364. (doi:10.1210/jc.2010-1207)

Appt SE, Chen H, Clarkson TB \& Kaplan JR 2012 Premenopausal antiMüllerian hormone concentration is associated with subsequent atherosclerosis. Menopause 19 1353-1359. (doi:10.1097/gme. Ob013e31825b4fe2)

Barker DJ 1995 Fetal origins of coronary heart disease. BMJ 311 171-174. (doi:10.1136/bmj.311.6998.171)

Cai J, Pardali E, Sanchez-Duffhues G \& ten Dijke P 2012 BMP signaling in vascular diseases. FEBS Letters 586 1993-2002. (doi:10.1016/j.febslet. 2012.04.030)

Catlin EA, Tonnu VC, Ebb RG, Pacheco BA, Manganaro TF, Ezzell RM, Donahoe PK \& Teixeira J 1997 Müllerian inhibiting substance inhibits branching morphogenesis and induces apoptosis in fetal rat lung. Endocrinology 138 790-796. (doi:10.1210/en.138.2.790)
Chong YH, Campbell AJ, Farrand S \& McLennan IS 2012 Anti-Müllerian hormone level in older women: detection of granulosa cell tumor recurrence. International Journal of Gynecological Cancer 22 1497-1499. (doi:10.1097/IGC.0b013e318270ac69)

Chong YH, Dennis NA, Connolly MJ, Teh R, Jones GT, van Rij AM, Farrand S, Campbell AJ \& McLennan IS 2013 Elderly men have low levels of anti-Müllerian hormone and inhibin B, but with high interpersonal variation: a cross-sectional study of the Sertoli cell hormones in 615 community-dwelling men. PLoS ONE 8 e70967. (doi:10.1371/journal. pone.0070967)

Dennis NA 2012 Is anti-Müllerian hormone a hormone. PhD Thesis, Anatomy. Dunedin: University of Otago, New Zealand. (available at: http://hdl.handle.net/10523/2558).

Dennis NA, Houghton LA, Jones GT, van Rij AM, Morgan K \& McLennan IS 2012 The level of serum anti-Müllerian hormone correlates with vitamin D status in men and women but not in boys. Journal of Clinical Endocrinology and Metabolism 97 2450-2455. (doi:10.1210/jc. 2012-1213)

Forsen TJ, Eriksson JG, Osmond C \& Barker DJ 2004 The infant growth of boys who later develop coronary heart disease. Annals of Medicine 36 389-392. (doi:10.1080/07853890410028438)

Griesinger G, Dafopoulos K, Buendgen N, Cascorbi I, Georgoulias P, Zavos A, Messini CI \& Messinis IE 2012 Elimination half-life of anti-Müllerian hormone. Journal of Clinical Endocrinology and Metabolism 97 2160-2163. (doi:10.1210/jc.2012-1070)

Jones GT 2011 The pathohistology of abdominal aortic aneurysm. In Diagnosis, Screening and Treatment of Abdominal, Thoracoabdominal and Thoracic Aortic Aneurysms, p 414Ed. RT Grundmann. Rijeka, Croatia: InTech.

Kelsey TW, Wright P, Nelson SM, Anderson RA \& Wallace WH 2011 A validated model of serum anti-Müllerian hormone from conception to menopause. PLoS ONE 6 e22024. (doi:10.1371/journal.pone. 0022024)

La Marca A, Broekmans FJ, Volpe A, Fauser BC \& Macklon NS 2009 Anti-Müllerian hormone (AMH): what do we still need to know? Human Reproduction 24 2264-2275. (doi:10.1093/humrep/dep210)

Lederle FA, Johnson GR, Wilson SE, Gordon IL, Chute EP, Littooy FN, Krupski WC, Bandyk D, Barone GW, Graham LM et al. 1997 Relationship of age, gender, race, and body size to infrarenal aortic diameter. The Aneurysm Detection and Management (ADAM) Veterans Affairs Cooperative Study Investigators. Journal of Vascular Surgery 26 595-601. (doi:10.1016/S0741-5214(97)70057-0)

Lee MM, Donahoe PK, Hasegawa T, Silverman B, Crist GB, Best S, Hasegawa Y, Noto RA, Schoenfeld D \& MacLaughlin DT 1996 Müllerian inhibiting substance in humans: normal levels from infancy to adulthood. Journal of Clinical Endocrinology and Metabolism 81 571-576. (doi:10.1210/jc.81.2.571)

Lowery JW \& de Caestecker MP 2010 BMP signaling in vascular development and disease. Cytokine \& Growth Factor Reviews 21 287-298. (doi:10.1016/j.cytogfr.2010.06.001)

MacLaughlin DT \& Donahoe PK 2004 Sex determination and differentiation. New England Journal of Medicine 350 367-378. (doi:10.1056/ NEJMra022784)

Morgan K, Dennis NA, Ruffman T, Bilkey DK \& McLennan IS 2011 The stature of boys is inversely correlated to the levels of their Sertoli cell hormones: do the testes restrain the maturation of boys? PLOS ONE 6 e20533. (doi:10.1371/journal.pone.0020533)

Paivansalo MJ, Merikanto J, Jerkkola T, Savolainen MJ, Rantala AO, Kauma H, Lilja M, Reunanen YA, Kesaniemi A \& Suramo I 2000 Effect of hypertension and risk factors on diameters of abdominal aorta and common iliac and femoral arteries in middle-aged hypertensive and control subjects: a cross-sectional systematic study with duplex ultrasound. Atherosclerosis 153 99-106. (doi:10.1016/S00219150(00)00374-9) 
Pearce WH, Slaughter MS, LeMaire S, Salyapongse AN, Feinglass J, McCarthy WJ \& Yao JS 1993 Aortic diameter as a function of age, gender, and body surface area. Surgery 114 691-697.

Pearson TA, Mensah GA, Alexander RW, Anderson JL, Cannon RO III, Criqui M, Fadl YY, Fortmann SP, Hong Y, Myers GL et al. 2003 Markers of inflammation and cardiovascular disease: application to clinical and public health practice: a statement for healthcare professionals from the Centers for Disease Control and Prevention and the American Heart Association. Circulation 107 499-511. (doi:10.1161/01.CIR. 0000052939.59093.45)

Ricci M, Mohapatra B, Urbiztondo A, Birusingh RJ, Morgado M, Rodriguez MM, Lincoln J \& Vatta M 2010 Differential changes in TGF-B/BMP signaling pathway in the right ventricular myocardium of newborns with hypoplastic left heart syndrome. Journal of Cardiac Failure 16 628-634. (doi:10.1016/j.cardfail.2010.03.007)

Rietzschel E \& De Buyzere M 2012 High-sensitive C-reactive protein: universal prognostic and causative biomarker in heart disease? Biomarkers in Medicine 6 19-34. (doi:10.2217/bmm.11.108)

Seifer DB, Baker VL \& Leader B 2011 Age-specific serum anti-Müllerian hormone values for 17,120 women presenting to fertility centers within the United States. Fertility and Sterility 95 747-750. (doi:10.1016/ j.fertnstert.2010.10.011)

Sonesson B, Lanne T, Hansen F \& Sandgren T 1994 Infrarenal aortic diameter in the healthy person. European Journal of Vascular Surgery $\mathbf{8}$ 89-95. (doi:10.1016/S0950-821X(05)80127-6)

Touboul PJ, Hennerici MG, Meairs S, Adams H, Amarenco P, Bornstein N, Csiba L, Desvarieux M, Ebrahim S, Fatar M et al. 2007 Mannheim carotid intima-media thickness consensus (2004-2006). An update on behalf of the Advisory Board of the 3rd and 4th Watching the Risk Symposium, 13th and 15th European Stroke Conferences, Mannheim, Germany, 2004, and Brussels, Belgium, 2006. Cardiovascular Diseases 23 75-80. (doi:10.1159/000097034)

Vainas T, Lubbers T, Stassen FR, Herngreen SB, van Dieijen-Visser MP, Bruggeman CA, Kitslaar PJ \& Schurink GW 2003 Serum C-reactive protein level is associated with abdominal aortic aneurysm size and may be produced by aneurysmal tissue. Circulation 107 1103-1105. (doi:10.1161/01.CIR.0000059938.95404.92)

Visser JA, Schipper I, Laven JS \& Themmen AP 2012 Anti-Müllerian hormone: an ovarian reserve marker in primary ovarian insufficiency. Nature Reviews. Endocrinology 8 331-341. (doi:10.1038/ nchembio.912)

Wang PY, Koishi K, McGeachie AB, Kimber M, Maclaughlin DT, Donahoe PK \& McLennan IS 2005 Müllerian inhibiting substance acts as a motor neuron survival factor in vitro. PNAS 102 16421-16425. (doi:10.1073/ pnas.0508304102)

Wang PY, Protheroe A, Clarkson AN, Imhoff F, Koishi K \& McLennan IS 2009 Müllerian inhibiting substance contributes to sex-linked biases in the brain and behavior. PNAS 106 7203-7208. (doi:10.1073/pnas. 0902253106)

Wittmann W \& McLennan IS 2011 The male bias in the number of Purkinje cells and the size of the murine cerebellum may require Müllerian inhibiting substance/anti-Müllerian hormone. Journal of Neuroendocrinology 23 831-838. (doi:10.1111/j.1365-2826.2011.02187.x)

Yeap BB, Hyde Z, Norman PE, Chubb SA \& Golledge J 2010 Associations of total testosterone, sex hormone-binding globulin, calculated free testosterone, and luteinizing hormone with prevalence of abdominal aortic aneurysm in older men. Journal of Clinical Endocrinology and Metabolism 95 1123-1130. (doi:10.1210/jc.2009-1696)

Received in final form 8 July 2013

Accepted 11 July 2013

Accepted Preprint published online 11 July 2013
(C) 2013 Society for Endocrinology Printed in Great Britain 